\title{
CYTOTOXICITY OF PIVOXIL ESTERS \\ OF ANTIVIRAL ACYCLIC NUCLEOSIDE PHOSPHONATES: ADEFOVIR DIPIVOXIL VERSUS ADEFOVIR
}

\author{
Zdeněk Zídek ${ }^{a}$, Eva Kmoníčkováa, Antonín Holýb \\ ${ }^{a}$ Institute of Experimental Medicine, Academy of Sciences, Videňská 1083, 14220 Prague 4, Czech Republic \\ ${ }^{b}$ Institute of Organic Chemistry and Biochemistry, Academy of Sciences, Flemingovo nám. 2, 16600 Prague 6, Czech \\ Republic \\ e-mail: zidekz@biomed.cas.cz
}

Received: June 10, 2005; Accepted: September 25, 2005

Key words: Adefovir/Adefovir dipivoxil/Pivoxil/Formaldehyde/Cytostatic activity/Cytocidal effects/Nitric oxide

Biological effectiveness of antiviral acyclic nucleoside phosphonate adefo vir, 9-[2-(phosphonomethoxy)ethy]ade nine (PMEA) and its more lipophilic (bis)pivaloyloxymethyl ester prodrug adefovir dipivoxil (bis-POM-PMEA) were compared under in vitro conditions in mammalian cell systems. Proliferation of murine splenocytes was inhibited in a concentration-dependent manner, the bis-POM-PMEA being more effective than PMEA. In contrast to PMEA, bis-POM-PMEA inhibited production of nitric oxide (NO) in macrophages activated with interferon- $\gamma$ (IFN- $\gamma$ ) and lipopolysaccharide (LPS). Viability of both splenocytes and macrophages remained uninfluenced by PMEA, whereas pronounced cytocidal effects were exhibited by bis-POM-PMEA. The $\mathrm{IC}_{50} \mathrm{~s}$ reached the values of $15 \mu \mathrm{M}$ and $30 \mu \mathrm{M}$ in cultures of macrophages and splenocytes, respectively (assayed at the interval of $24 \mathrm{hrs}$ ). The effects could partly be mimicked by formaldehyde, a decomposition product of the pivoxil moiety of bis-POM-PMEA. The other possible product, pivalic acid, was ineffective in this respect. The present data are consistent with the view that pivoxil prodrug of PMEA, bis-POM-PMEA possesses enhanced but also broader spectrum of biological effects than the parent compound.

\section{INTRODUCTION}

Acyclic nucleoside phosphonate 9-[2-(phosphonomethoxy)ethy]adenine (PMEA; adefovir) is a recognized antiviral agent possessing both antiherpesvirus and antiretroviral activities including anti-HIV effects ${ }^{1-4}$. The major disadvantage of this class of compounds under therapeutic usage is, however, rather poor intracellular delivery, intestinal permeation and limited oral bioavailability ${ }^{5,6}$. Pharmaceutic formulations which would overcome these obstacles are therefore intensively explored. The negative charge of the PMEA molecule can be reduced through the introduction of the lipophilic (bis)pivaloyloxymethyl (pivoxil) moiety, giving rise to bis-POM-PMEA, i.e. adefovir dipivoxil. The prodrug shows considerably enhanced oral bioavailability in comparison with the parent structure of PMEA (ref. ${ }^{5,6}$ ), and has been approved by FDA and EMEA for general treatment of hepatitis B $\left(\mathrm{Hepsera}^{\circledR}\right)$. Not only antiviral effectiveness ${ }^{7}$ but also more prominent antiarthritogenic activty of bis-POM-PMEA over PMEA ${ }^{8}$ have been reported. We have shown recently that PMEA suppresses proliferation of lymphocytes ${ }^{9}$ and in contrast to a number of other acyclic nucleoside phosphonates it does not augment production of immune-activated production of nitric oxide by macrophages ${ }^{10}$. The aim of this study was to investigate the influence of PMEA pivoxilation on these cell functions.

\section{MATERIALS AND METHODS}

\section{Animals}

Female mice of the inbred strain C57BL/6, 7-9 wks old, were purchased from Charles River Deutschland (Sulzfeld, Germany). They were kept in transparent plastic cages in groups of eight, and maintained in an Independent Environmental Air Flow Cabinet (ESI Flufrance, Wissous, France). Lighting was set on 0600 to $1800 \mathrm{~h}$, temperature at $22^{\circ} \mathrm{C}$.

\section{Compounds}

9-[2-(Phosphonomethoxy)ethy] adenine (PMEA; adefovir) was synthesized in-house (Inst. Organic Chemistry and Biochemistry) according to the procedure described
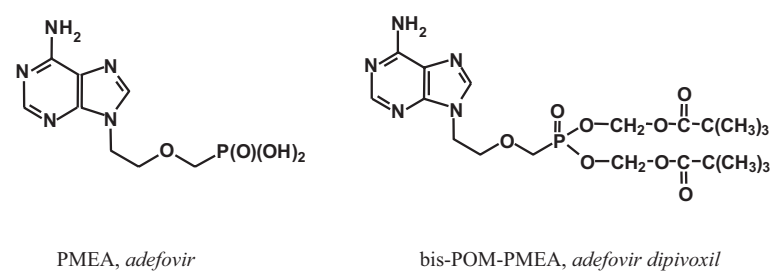

Fig. 1. Chemical structure of test acyclic nucleoside phosphonates. 
elsewhere ${ }^{11,12}$. The (bis)pivaloyloxymethyl ester prodrug adefovir dipivoxil (bis-POM-PMEA) was kindly donated by Gilead Sciences (Foster City, CA). Their structure is shown in Fig. 1. Stock solutions were prepared in incomplete phenol red-free RPMI-1640 culture medium containing $\mathrm{NaHCO}_{3}$ (Sigma-Aldrich, Prague, CR). Working concentrations were prepared by diluting the stock solutions in complete medium RPMI-1640 (see below) and used fresh.

\section{Culture medium and other reagents}

Complete RPMI-1640 medium contained $10 \%$ heat-inactivated fetal bovine serum, $2 \mathrm{mM}$ L-glutamine, $50 \mu \mathrm{g} / \mathrm{ml}$ gentamicin, and $5 \times 10^{5}$ M 2-mercaptoethanol (all Sigma). Recombinant mouse interferon- $\gamma$ (IFN- $\gamma$ ) was purchased from R\&D Systems (Minneapolis, MN), lipopolysaccharide (LPS) of S. typhimurium origin from Difco Labs (Detroit, MI), the LDH cytotoxicity detection kit from Boehringer Mannheim (Germany), and methyl- ${ }^{3} \mathrm{H}$-thymidine (specific activity $185 \mathrm{GBq} / \mathrm{mmol}$ ) from Amersham (Little Chalfont, UK). Pivalic acid was obtained from Sigma.

\section{Lymphocytes and lymphocyte proliferation assay}

Single-cell suspension of splenocytes was prepared by passing fragmented pooled spleens of mice through a fine nylon sieve. Erythrocytes were removed using the red blood cells lysing buffer (Sigma) containing $0.83 \%$ ammonium chloride in $0.01 \mathrm{M}$ Tris- $\mathrm{HCl}, \mathrm{pH} 7.5$. After repeated thorough washing the cells were seeded in triplicate wells of 96-well U-bottom cell culture plates (Nunc, Roskilde, Denmark). The number of cells was $5 \times 10^{5} /$ well in final $100 \mu \mathrm{l}$. They were cultured for $72 \mathrm{~h}$ in the presence or absence of mitogens (ConA, $2.5 \mu \mathrm{g} / \mathrm{ml}$ or LPS, $5 \mu \mathrm{g} / \mathrm{ml}$ ) in Heraeus incubator keeping $37{ }^{\circ} \mathrm{C}, 5 \% \mathrm{CO}_{2}$, $100 \%$ relative humidity.

PMEA and bis-POM-PMEA were added immediately after mitogens. Six hours prior to the collection of cells, they were pulsed with $0.5 \mu \mathrm{Ci}$ of methyl- ${ }^{3} \mathrm{H}$-thymidine. Cells were harvested onto glass microfiber filters using Dynatech Multimash Harvestor 2000. Thymidine incorporation into DNA (cpm) was determined via scintillation counting.

\section{Macrophages and macrophage nitric oxide (NO) production}

Mice, sacrificed by cervical dislocation, were injected intraparitoneally with $8 \mathrm{ml}$ sterile saline. Collected and pooled lavage cells were washed, resuspended in culture medium and seeded into 96-well flat-bottom Nunc microplates in $100-\mu 1$ volumes. Adherent peritoneal cells (macrophages) were isolated by incubating the cells for $2 \mathrm{~h}$ at $37{ }^{\circ} \mathrm{C}, 5 \% \mathrm{CO}_{2}$, and then thrice vigorously shaking the plate and washing to remove non-adherent cells. Cultures were maintained with or without addition of PMEA and bis-POM-PMEA and in the absence or presence of IFN- $\gamma(5000 \mathrm{pg} / \mathrm{ml})$ plus LPS $(1 \mu \mathrm{g} / \mathrm{ml})$ in Heraeus incubator for $24 \mathrm{~h}$. All experimental variants were set in triplicate.
The concentration of nitrites in supernatants was taken as a measure of NO production ${ }^{13,14}$. It was detected in individual cell-free samples $(50 \mu 1)$ incubated for $10 \mathrm{~min}$ at $37{ }^{\circ} \mathrm{C}$ with an aliquot of a Griess reagent (1\% sulphanilamide $/ 0.1 \%$ naphtylendiamine $\left./ 2.5 \% \mathrm{H}_{3} \mathrm{PO}_{4}\right)$. The absorbance at $540 \mathrm{~nm}$ was recorded using a microplate spectrophotometer (Tecan, Austria). A nitrite calibration curve was used to convert absorbance to $\mu \mathrm{M}$ nitrite.

\section{Determination of cell viability}

Cell death was analysed using the LDH assay. It is based on the determination of lactate dehydrogenase activity released from the cytosol of damaged cells into the supernatant. The cell supernatants were diluted $1: 1$ and mixed with an aliquot of the LDH kit. After 30-min incubation in the dark at ambient temperature, the reaction was stopped with $2 \mathrm{~N} \mathrm{HCl}$. Differences between absorbances at 492 and $690 \mathrm{~nm}$ were evaluated. The percentage cytotoxicity of test samples was related to the control samples and to the samples with $100 \%$ dead cells evoked by $1 \%$ Triton, according to the formula: [(exp. value - control value) / (Triton value - control value)] $\times 100$. All control and experimental variants were run in triplicate.

\section{Data analysis}

Analysis of variance (ANOVA) with subsequent Dunnett's multiple comparison test, and graphical presentation of data were done using the Prism program (GraphPad Software, San Diego, CA).

\section{RESULTS}

\section{Antiproliferative effects of PMEA and bis-POM-PMEA}

The following values (means \pm SEM) of incorporation of ${ }^{3} \mathrm{H}$-thymidine into DNA were found in controls (drugs absent): 1,700 $\pm 138 \mathrm{cpm}$ for resident, mitogennonstimulated cells, 22,397 $\pm 1,059 \mathrm{cpm}$ for LPS-stimulated, and 128,473 \pm 1,690 cpm for ConA-stimulated cells. Proliferation of nonstimulated and mitogen-stimulated lymphocytes was differentially inhibited by PMEA and bis-POM-PMEA (Fig. 2). Expressed as a percentage of corresponding control values, the inhibitory effects run in parallel in individual experimental groups. The bis-POMPMEA proved to be significantly more potent $(\mathrm{P}<0.01)$ than PMEA in suppressing proliferation of all nonstimulated ( $\mathrm{IC}_{50} \mathrm{~s}$ : 2.9 and $20.4 \mu \mathrm{M}$, respectively), LPS-stimulated (1.7 and $13.8 \mu \mathrm{M}$, respectively), and ConA-treated (0.44 and $1.02 \mu \mathrm{M}$, respectively) cells.

\section{Effects of PMEA and bis-POM-PME on nitric oxide (NO) production}

Production of NO, triggered primarily in mouse peritoneal macrophages by LPS ( $10 \mathrm{pg} / \mathrm{ml})$ plus IFN- $\gamma$ (5000 pg/ml), remained uninfluenced by PMEA (Fig. 3). PMEA was ineffective even in as high concentrations as $500 \mu \mathrm{M}$. On the other hand, effects of bis-POM-PMEA on NO production were strongly inhibitory. The dose of 


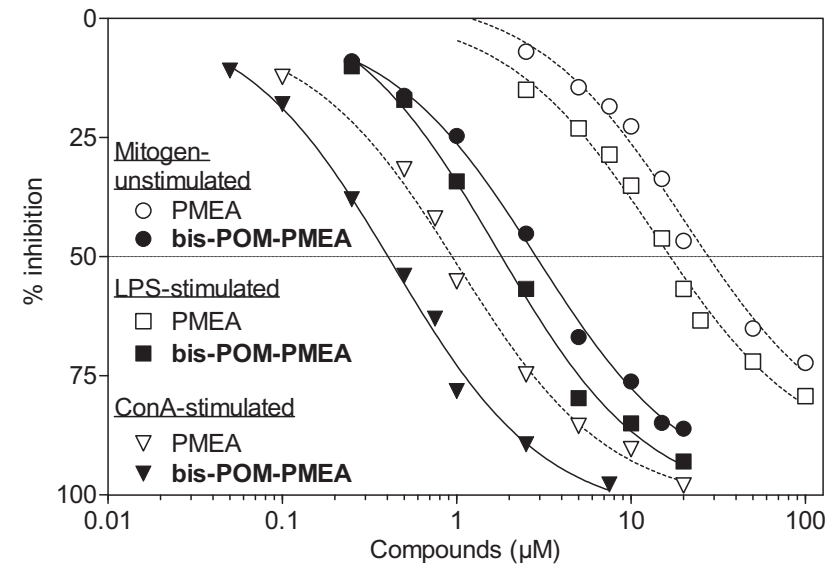

Fig. 2. Antiproliferative effects of PMEA and bis-POMPMEA. Mouse lymphocytes were cultured for 72 $\mathrm{h}$ in the absence or presence of B-cell mitogen LPS and T-cell mitogen ConA. Six hours prior to the collection of cells, they were pulsed with $0.5 \mu \mathrm{Ci}$ of methyl $-{ }^{3} H$-thymidine. Its incorporation into DNA was determined by scintillation counting. Control cpm values are shown in Results.

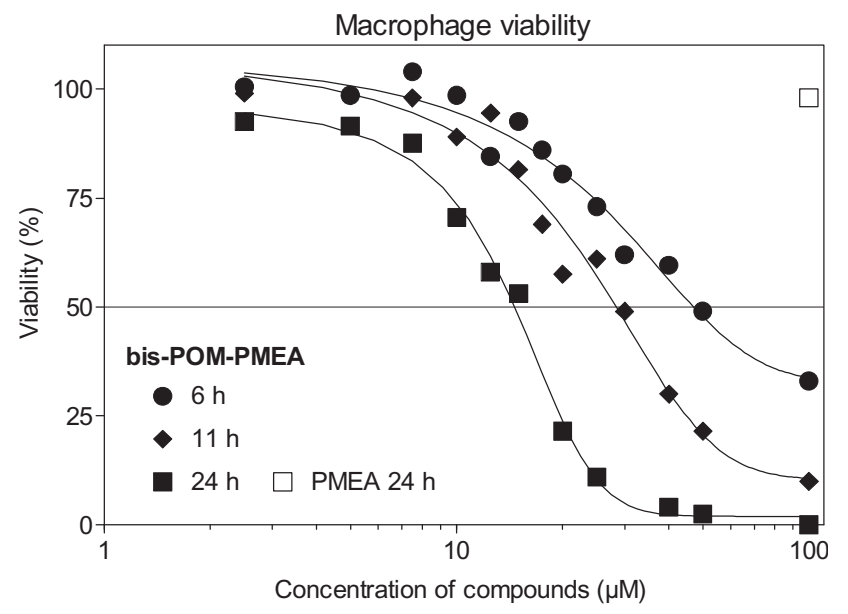

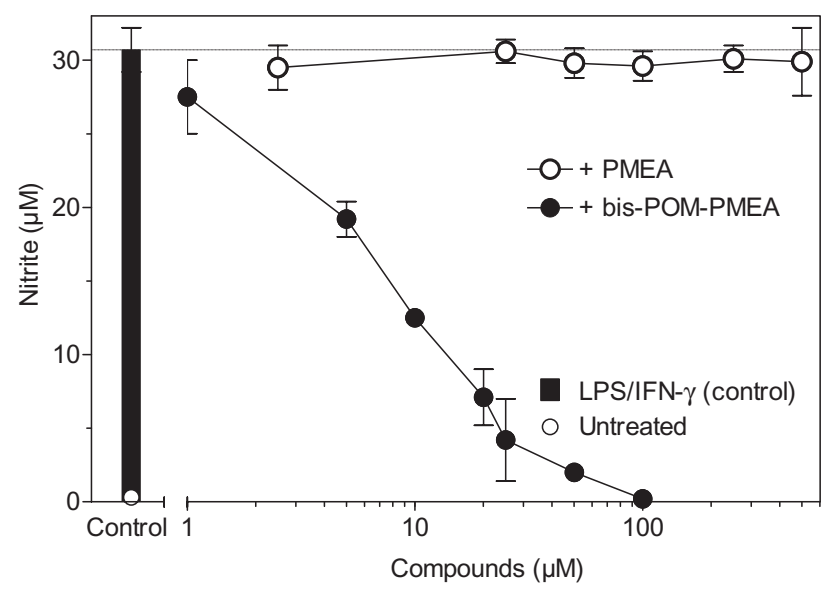

Fig. 3. Effects of PMEA and bis-POM-PMEA on production of NO by macrophages activated with LPS+IFN- $\gamma$. Nitrite concentration in supernatants of cells cultured for $24 \mathrm{~h}$ was determined by Griess reagent.

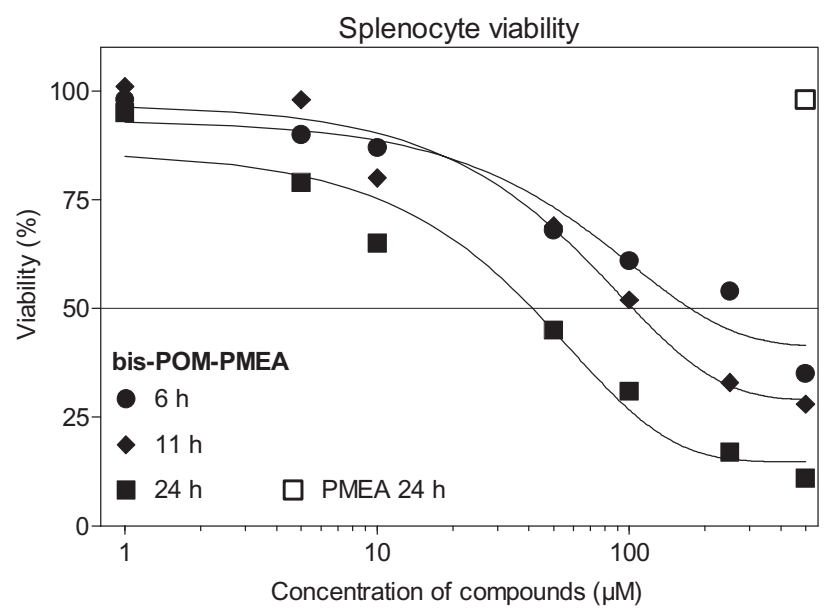

Fig. 4. Effect of bis-POM-PMEA and PMEA on viability of murine macrophages and lymphocytes. The LDH assay was performed at indicated time intervals subsequent to the addition of test compounds.

approximately $5 \mu \mathrm{M}$ reduced the production of NO by about $50 \%$.

\section{Cytocidal effects of bis-POM-PMEA}

Whereas even high doses $(100-500 \mu \mathrm{M})$ of PMEA did not influence viability of cells (Fig. 4), bis-POM-PMEA proved to possess remarkable cytocidal activity. The $\mathrm{LC}_{50}$, determined at the interval of $24 \mathrm{~h}$, reached the value of $15 \mu \mathrm{M}$ for macrophages, and $30 \mu \mathrm{M}$ for splenocytes. The effects were time-dependent, the significant inhibition of viability of both macrophages and lymphocytes being apparent as early as 5-6 $\mathrm{h}$ following the addition of bisPOM-PMEA to cells (Fig. 4).
Comparison of biological effects of bis-POM-PMEA with the effects of formaldehyde and pivalic acid

As compared to bis-POM-PMEA, formaldehyde was less potent to inhibit production of NO by macrophages (Fig. 5). Pivalic acid was free of the NO-suppressive effect. Similarly, only formaldehyde, but not pivalic acid, showed moderate cytocidal activity (Fig. 6).

\section{DISCUSSION}

Expression of biological potential of PMEA, i.e. 9-[2(phosphonomethoxy)ethy]adenine (adefovir) is restricted by a relatively high anionic charge of this molecule, brought about by the phosphonate side chain, which 


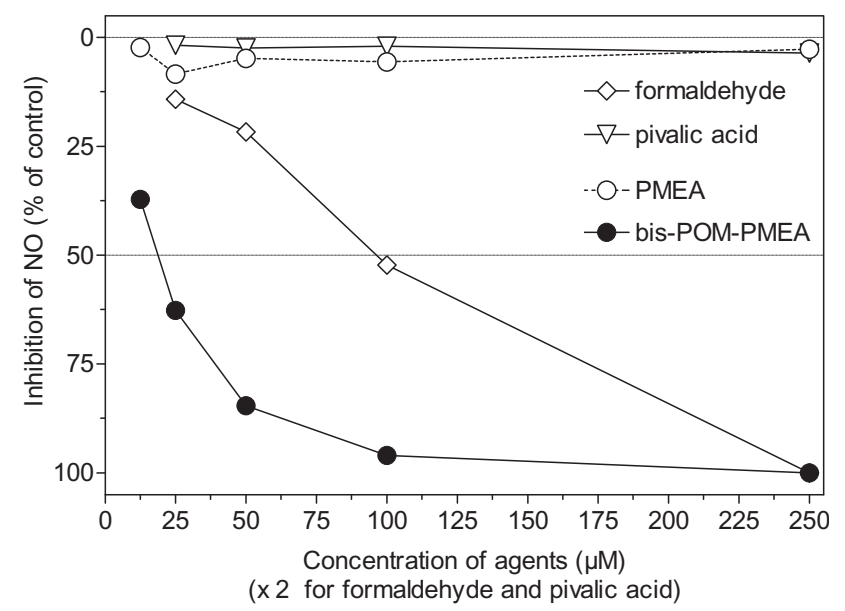

Fig. 5. Bis-POM-PMEA- and formaldehyde-induced suppression of NO production in macrophages stimulated with LPS+IFN- $\gamma$. Control value for the cells cultivated without the test compounds was $42 \pm$ $2.7 \mu \mathrm{M}$ nitrite. Formation of NO was inspected after 24-h culture.

makes it otherwise resistant to metabolism. The pivoxil prodrug, i.e. the (bis)pivaloyloxymethyl ester of PMEA, bis-POM-PMEA (adefovir dipivoxil), overcomes partially this obstacle and has been found to possess higher virostatic efficacy than parent PMEA. Both compounds are transported across the membrane by endocytosis ${ }^{15}$. Once in the cell, bis-POM-PMEA is cleaved gradually to the parent drug ${ }^{6}$, and is subsequently phosphorylated to its mono- and diphosphate (analogues of dADP and dATP). These anabolites are alternative substrates and inhibitors of DNA polymerases ${ }^{16}$ and act as chain terminators of the DNA synthesis de novo ${ }^{11,17}$. The cleavage of bis-POMPMEA and, in particular, the subsequent phosphorylation strongly depend on the cell type and on a variety of enzymes ${ }^{18-20}$.

We have found that the both drugs inhibit proliferation of murine splenocytes, irrespective of the kind of mitogen stimulation, or without any immune stimulation. The bis-POM-PMEA is several-fold more effective than parent PMEA. As far as the intracellular concentration has been shown to be a crucial factor determining biological efficacy of PMEA ${ }^{21,22}$, it could be presumed that the enhanced effectiveness of bis-POM-PMEA results from the different abilities of PMEA versus bis-POM-PMEA to permeate across cell membranes.

In sharp contrast to a quantitative character of these differences, the influence on production of NO is a novel property and is bound solely to bis-POM-PMEA. Even enormously increased concentrations of PMEA (up to $500 \mu \mathrm{M}$ ) were absolutely devoid of any positive and negative interference with biosynthesis NO. However, the introduction of pivoxil moiety in the molecule of bisPOM-PMEA led to the occurrence of inhibitory effects on NO production

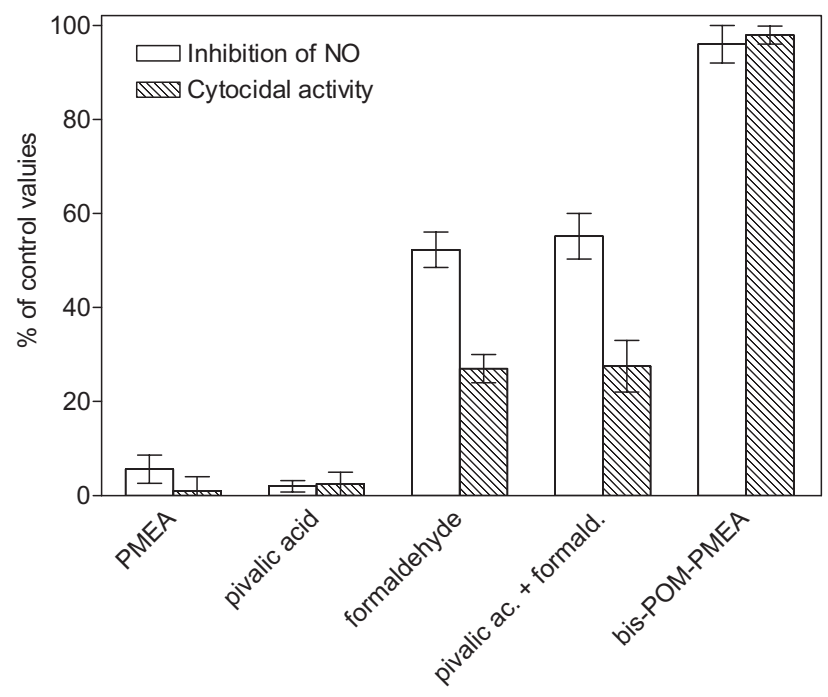

Fig. 6. Comparison of the NO-inhibitory and cytocidal effects of PMEA (100 $\mu \mathrm{M})$, bis-POM-PMEA $(100 \mu \mathrm{M})$, and its decomposition products formaldehyde $(200 \mu \mathrm{M})$ and pivalic acid $(200 \mu \mathrm{M})$. The both effects are statistically significantly correlated (Pearson $\mathrm{r}=0.93, \mathrm{P}<0.05)$.

This finding prompted us to investigate possible cytocidal potential of bis-POM-PMEA, as well as a profile of biological effects of decomposition products of the pivoxil moiety, i.e. formaldehyde and pivalic acid. Indeed, bisPOM-PMEA was found to remarkably decrease viability of both lymphocytes and macrophages. Similarly, in agreement with other reports ${ }^{23}$, formaldehyde (but not pivalic acid) decreased the cell viability. Furthermore, it inhibited production of NO by macrophages. It may be presumed that enhanced antiproliferative effects of bis-POM-PMEA are due to improved transmembrane permeability, but at least in part they are influenced by formaldehyde-induced dying the cells. Inhibition of NO production seems to be however entirely dependent on formation of formaldehyde, and not on enhanced intracellular concentration of PMEA following administration of the prodrug. It should be noted that formaldehyde (as well as pivalic acid) was applied at concentrations that could theoretically arise if all pivoxil moieties of bis-POM-PMEA molecule are transformed to formaldehyde and pivalic acid. Despite of this, all inhibitory effects of bis-POM-PMEA were more pronounced than those of formaldehyde. Plausible explanation for the discrepancy might be a difference in intracellular accumulation of formaldehyde reached after its direct administration into the cell cultures, or alternatively delivered indirectly by bis-POM-PMEA in the form of pivoxil ancestry. It cannot be excluded that intracellular concentrations of formaldehyde are higher after treatment of cells with bis-POM-PMEA than after addition of exogenous formaldehyde. This question remains to be investigated.

Apart from the inhibitory effects on NO formation and cell viability, formaldehyde has been shown to possess a number of other unwanted effects. It has been sug- 
gested to contribute to allergic respiratory disease ${ }^{24}$, to be a risk factor for initiation of endothelial injury leading to atherosclerosis ${ }^{25}$, and for neurogenic inflammation ${ }^{26}$. Inasmuch as some drugs including antibiotics ${ }^{27-29}$ and anticancer agents ${ }^{30,31}$ are pharmaceutically formulated as pivoxil prodrugs, careful evaluation of their possibly formaldehyde-related side effects and therapeutic implications warrant special consideration.

\section{ACKNOWLEDGEMENT}

Financial support from the Centre for New Antivirals and Antineoplastics 1M6138896301 is gratefully acknowledged.

\section{REFERENCES}

1. De Clercq E. (1991) Broad-spectrum anti-DNA virus and anti-retrovirus activity of phosphonomethoxyalkylpurines and -pyrimidines. Biochem Pharmacol 42, 963-72.

2. Pauwels R, Balzarini J, Schols D, Baba M, Desmyter J, Rosenberg I, Holý A, De Clercq E. (1988) Phosphonomethoxyethyl purine derivatives, a new class of anti-human immunodeficiency virus agents. Antimicrob Agents Chemother 32, 1025-30.

3. Thormar H, Balzarini J, Holý A, Jindřich J, Rosenberg I, Debyster Z, Desmyter J, De Clercq E. (1993) Inhibition of visna virus replication by 2',3'-dideoxynucleosides and acyclic nucleoside phosphonate analogs. Antimicrob Agents Chemother 37, 2540-4.

4. Holý A. (2003) Phosphonomethoxyalkyl analogs of nucleotides. Curr Pharmaceut Design 9, 2567-92.

5. Balzarini J, Naesens L, Slachmuylders J, Niphuis H, Rosenberg I, Holý A, Schellekens H, De Clercq E. (1991) 9-(2-phosphonometh oxyethyl)adenine (PMEA) effectively inhibits retrovirus replication in vitro and simian immunodeficiency virus infection in rhesus monkeys. AIDS 5, 21-8.

6. Cundy KC, Fishback JA, Shaw JP, Lee ML, Soike KF, Visor GC, Lee WA. (1994) Oral bioavailability of the antiretroviral agent 9. (2-phosphonylmethoxyethyl)adenine (PMEA) from three formulations of the prodrug bis(pivaloyloxymethyl)-PMEA in fasted male cynomolgus monkeys. Pharm Res 11, 839-43.

7. Naesens L, Balzarini J, Bischofberger N, De Clercq E. (1996) Antiretroviral activity and pharmacokinetics in mice of oral bis(pivaloyloxymethyl)-9-(2-phosphonomethoxyethyl)adenine, the bis(pivaloylomethyl) ester prodrug of 9-(2-phosphonylmethoxyethyl)adenine. Antimicrob Agents Chemother 40, 22-8.

8. Zídek Z, Holý A, Franková D, Otová B. (1995) Suppression of adjuvant arthritis by some acyclic nucleotide analogs. Eur J Pharmacol 286, 307-10.

9. Zídek Z, Potměšil P, Holý A. (2003) Cytostatic activity of antiviral acyclic nucleoside phosphonates in rodent lymphocytes. Toxicol Appl Pharmacol 192, 246-53.

10. Zidek Z, Potměšil P, Kmoníčková E, Holý A. (2003) Immunobiological activity of $N$-[2-(phosphonomethoxy)alkyl] derivatives of $N^{6}$-substituted adenines, and 2,6-diaminopurines. Eur J Pharmacol 475, 149-59.

11. Holý A, Votruba I, Merta A, Černý J, Veselý J, Vlach J, Šedivá K, Rosenberg I, Otmar M, Hřebabecký H, Trávníček M, Vonka V, Snoeck R, De Clercq E. (1990) Acyclic nucleotide analogues: synthesis, antiviral activity and inhibitory effects on some cellular and virus-encoded enzymes in vitro. Antiviral Res 13, 295-311.

12. Holý A, Votruba I, Tlouštová E, Masojídková M. (2001) Synthesis and cytostatic activity of $N$-[2-(phosphonomethoxy)alkyl] derivatives of $N^{6}$-substituted adenines, 2,6-diaminopurines and related compounds. Collect Czech Chem Commun 66, 1545-92.
13. Amber IJ, Hibbs JBJ, Taintor RR, Vavrin Z. (1988) Cytokines induce an L-arginine-dependent effector system in nonmacrophage cells. J Leukoc Biol 44, 58-65.

14. Marletta MA, Yoon PS, Iyengar R, Leaf CD, Wishnok JS. (1988) Macrophage oxidation of L-arginine to nitrite and nitrate. Biochemistry 27, 8706-11.

15. Cihlář T, Rosenberger I, Votruba I, Holý A. (1995) Transport of 9-(2-phosphonomethoxyethyl)adenine across plasma membrane of HeLa S 3 cells is protein mediated. Antimicrob Agents Chemother 39, 117-24.

16. Kramata P, Votruba I, Otová B, Holý, A. (1996) Different inhibitory potencies of acyclic phosphonomethoxyalkyl nucleotide ana$\log$ s toward DNA polymerases $\alpha, \delta$ and $\varepsilon$. Mol Pharmacol 49, 1005-11.

17. Votruba I, Trávníček M, Rosenberg I, Otmar M, Merta A, Hřebabecký H, Holý A. (1990) Inhibition of avian myeloblastosis virus reverse transcriptase by diphosphates of acyclic phosphonylmethyl nucleotide analogues. Antiviral Res 13, 287-93.

18. Bronson JJ, Ho HT, De Boeck H, Woods K, Ghazzouli I, Martin JC, Hitchcock MJ (1989) Biochemical pharmacology of acyclic nucleotide analogues. Ann NY Acad Sci 616, 398-407.

19. Balzarini J, De Clercq E. (1991) 5-Phosphoribosyl 1-pyrophosphate synthetase converts the acyclic nucleoside phosphonates 9-(3-phosphonylmethoxypropyl)adenine and 9-(2-phosphonylmethoxyethyl)adenine directly to their antivirally active diphosphate derivatives. J Biol Chem 266, 8686-9.

20. Merta A, Votruba I, Jindřich J, Holý A, Cihlář T, Rosenberg I, Otmar M, Tchaou HY (1992) Phosphorylation of 9-(S)-(3-hydroxy2-phosphonylmethoxypropyl)adenine by AMP (dAMP) kinase from L1210 cells. Biochem Pharmacol 44, 2067-77.

21. Balzarini J, Hao Z, Herdewijn D, Johns DG, De Clercq E. (1991) Intracellular metabolism and mechanism of anti-retrovirus action of 9-(2-phosphonylmethoxyethyl)adenine (PMEA), a potent antiHIV compound. Proc Natl Acad Sci USA 88, 1499-503.

22. Palu G, Stefanelli S, Rassu M, Parolin C, Balzarini J, De Clercq E. (1991) Cellular uptake of phosphonomethoxyalkyl derivatives. Antiviral Res 16, 115-9.

23. Poirier M, Fournier M, Brousseau P, Morin A. (2002) Effects of volatile aromatics, aldehydes, and phenols in tobacco smoke on viability and proliferation of mouse lymphocytes. J Toxicol Environ Health A 65, 1437-51.

24. Smedley J. (1996) Is formaldehyde an important cause of allergic respiratory disease? Clin Exp Allergy 26, 247-9.

25. Yu P, Zuo DM. (1996) Formaldehyde produced endogenously via deamination of methylamine. A potential risk factor for initiation of endothelial injury. Atherosclerosis 120, 189-97.

26. Damas J, Liégeois J-F. (1999) The inflammatory reaction induced by formalin in the rat paw. Naunyn-Schmied Arch Pharmacol 359, 220-27.

27. Sjovall J, Huitfeldt B, Magni L, Nord CE. (1986) Effect of betalactam prodrugs on human intestinal microflora. Scand J Infect Dis 49 (Suppl.), 73-84.

28. Abrahamsson K, Eriksson BO, Holme E, Jodal U, Lindstedt S, Nordin I. (1994) Impaired ketogenesis in carnitine depletion caused by short-term administration of pivalic acid prodrug. Biochem Med Metab Biol 52, 18-21.

29. Bryson HM, Brogden RN. (1993) Cefetamet pivoxil. A review of its antibacterial activity, pharmacokinetic properties and therapeutic use. Drugs 45, 589-621.

30. Farquhar D, Khan S, Srivastva DN, Saunders PP. (1994) Synthesis and antitumor evaluation of bis[(pivaloyloxy)methyl] 2'-deoxy-5fluorouridine 5'-monophosphate (FdUMP): A strategy to introduce nucleotides into cells. J Med Chem 37, 3902-9.

31. Siu LL, Von Hoff DD, Rephaeli A, Izbicka E, Cerna C, Gomez L, Rowinsky EK, Eckhardt SG. (1998) Activity of pivaloyloxymethyl butyrate, a novel anticancer agent, on primary human tumor colony-forming units. Investigat New Drugs 16, 113-9. 